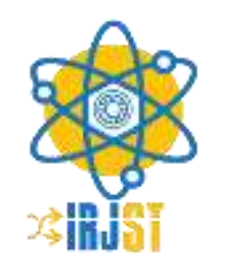

Available online at https://www.irjst.com/

International Research Journal of Science and Technology

ISSN: 2707-3955

DOI: https://doi.org/10.46378/irjst.2021.020207

\title{
Efficiency and Acceptability of Mixed Reality Application of Solar System in Teaching Science
}

\author{
Michael G. Albino ${ }^{1 *}$, Jerico A. Lazaro ${ }^{2}$, Ahljhun L. Olis ${ }^{3}$, Rica B. Requelman ${ }^{4}$, Xyra N. Sanchez $^{5}$ \\ ${ }^{1-5}$ President Ramon Magsaysay State University, Castillejos, Zambales, Philippines, 2208
}

\begin{tabular}{llll}
\multicolumn{2}{l}{ Paper Status } & & \\
\cline { 1 - 1 } Received & $:$ & Feb 2021 \\
Accepted & $:$ & Mar 2021 \\
Published & $:$ & Mar & 2021
\end{tabular}

Key Words

Mixed Reality

Solar System

Virtual Environment

3D Model

\begin{abstract}
The constant changed in technology and the new innovations was undoubtedly contributed largely to education. Mixed Reality (MR), one of the newest technologies and a very promising tool that allows merging of physical reality and virtual environment to enhance teaching and learning process for better and engaging learning experiences. The researchers proposed a "Mixed Reality Application of Solar System" as an assistive tool by the teachers in teaching of the lessons faster through visualizing 3D models of planets in the solar system. In this paper, the researchers made use of descriptive-qualitative technique and a survey in gathering data. The study has undergone testing and evaluation with the help of five (5) IT experts as alpha testers and twenty (20) STEP students of Subic National High School as beta testers using the ISO 9126-1 software quality standards criteria. Alpha tests overall rated mean of 4.53, interpreted as "Excellent" on Functionality, 4.13 "Very Good" on Usability, 4.00 "Very Good" on Efficiency and 4.40 "Excellent" on Portability while beta tests overall rated mean of 4.78 "Excellent" on Functionality, 4.66 'Excellent" on Usability, 4.60 "Excellent" on Efficiency and 4.80 "Excellent" on Portability. Respondents were satisfied on the performance of the mixed reality application as manifested on the results of the survey, 4.15 "Very Good" on users' acceptance and 4.50 "Excellent: on experts' acceptance. Based on the data gathered from the respondents, the researchers recommended the use of the developed mixed reality application in teaching science. Respondents recommendations were mainly focused on the improvement of the graphics and user interface through adjustment of interactive buttons in the application. The researchers recommended for the future enhancement of the application to the future researchers the capability of the mixed reality application to be available in iOS and personal computers.
\end{abstract}

Copyright (0 2021: Michael G. Albino. This is an open-access distribution, and reproduction in any medium provided Access article distributed under the Creative Commons Attribution License the original work is properly cited License, which permits unrestricted use.

Citation: Michael G. Albino, Jerico A. Lazaro, Ahljhun L. Olis, Rica B. Requelman, Xyra N. Sanchez. "Efficiency and acceptability of mixed reality application of solar system in teaching science" International Research Journal of Science and Technology, 2 (2), 413-422, 2021.

\section{Introduction}

Mixed-Reality (MR) presents new computing platform that rising from the present fields of Augmented- and Virtual-Reality (AR/VR). MR blends the physical and also the digital worlds into one house, employing a combination of leading-edge optical hardware and

\footnotetext{
* Corresponding Author: Michael G. Albino

Magsaysay State University, Philippines.

Email: malbino0203@gmail.com
}

computing artificial intelligence software system. Teaching and learning with technology, before now, was principally restricted to supplementary collaboration tools for communication: learning management systems and electronic texts. There are two major approaches of utilizing AR technology in science education, which are named as image-based AR and location-based AR [1]. Study focused on developing usability principles for the development and evaluation of smartphone applications using AR 
technology [2]. The study which aimed to explore whether the integration of virtual reality and augmented reality used in a specially designed science book could improve the students' science concept learning outcomes [3].

Augmented Reality is considered less obstructive than VR where the user is immersed in the synthetic environment with being disconnected from the real world. AR allows the user to see the real world with adding virtual objects over the real world. Therefore, AR replaces parts of real world instead of completely replacing it. This feature of merging the real world with virtual objects makes the AR very appealing to users. This feature allowed AR to make up for one of the imperfections of MR by providing the user with the access to the real and virtual environments. A review on $\mathrm{AR}$ in the context of mobile learning where they analyzed six mobile learning systems that utilized AR as a key component. Their comparison taxonomy featured six variables, mostly focusing on nontechnical aspects: device/technology, mode of interaction/learning design, method of sensory feedback, personal/shared experience, fixed/static or portable experience, and learning activities [4].

The proposed application has the ability to visualize 3D model of the Solar System as a new teaching tool in Subic National High School, STEP Strand. Through the use of an android mobile device and was connected to a virtual reality box (VR box) the students could visualize the solar system and its description of each planet. This innovative technology can aid with the transition between these stages. The enhancement of reality with synthetic images allows to perform tasks more easily, such as the collaboration between people who are at different locations. Collaborative manufacturing, assembly tasks or education can be conducted remotely, even if the collaborators do not physically meet. This paper reviews both past and recent research, identifies benefits and limitations, and extracts design guidelines for the creation of collaborative Mixed Reality applications in technical settings [5].

\subsection{Conceptual Framework}

This framework shows the overall outline of the study. It can be expressed by using the input-process-output (IPO), a process is viewed as a series of boxes (processing elements) connected by inputs and outputs. Information or material objects flow through a series of task or activities based on a set of rules or description points. What goes in is the input; what causes the change is the process; what comes out is the output. The IPO model provided the general structure and guide for the direction of study.

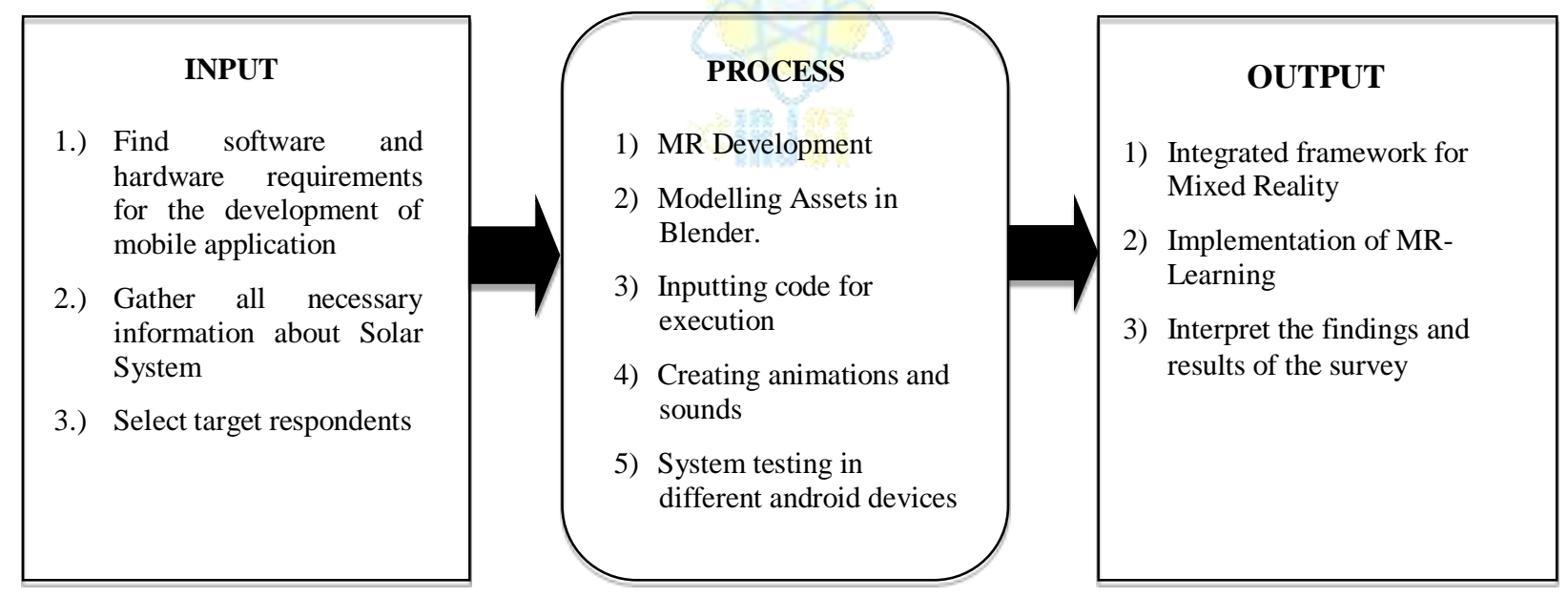

Figure 1. Paradigm of the study

\subsection{Statement of the Problem}

The main purpose of this system was to develop a Mixed Reality (MR) mobile application of the Solar System that will be used as tool in teaching science at Subic National High School-STEP, during the school year 2018-2019.

\section{Specifically, it sought to answer the following:}

1. What is the student's perception towards the systems efficiency according to the following criteria?

1.1 Functionality

1.2 Usability

\subsection{Efficiency}

1.4 Portability

2. What is the expert's perception towards the systems efficiency according to the following criteria?
2.1Functionality
2.2 Usability
2.3 Efficiency
2.4 Portability

How would the students accept the use of the system? 


\subsection{Scope and Limitation}

The researchers' aims to develop a Mixed Reality in mobile application that will help improve the way the teachers present their lesson in Solar System. The software application will give the basic information for each planet that will clearly present the planets' views. Through this application students and teachers will be having a realistic view of the planets by using the virtual reality box and mobile phone. The application will replace the usual and traditional way of the teachers in presenting their lessons. The researchers utilized the use of Blender Software for $3 \mathrm{~d}$ modelling of the planets and Unity 3D for the development of the application that uses Vuforia cloud as its database for the target image. The MR application were installed in an android mobile device following its minimum hardware and software requirements to function and was connected to a virtual reality box (VR box) for the visualization of the whole project. The main scope of the study is to present a 3D visualization of the planets in the solar system in a form of Mixed Reality application.

\section{Material and Methods}

\subsection{Methods of Research}

Descriptive qualitative study provided and facilitated researchers to generate findings closer to the raw data than other qualitative studies. The goal of qualitative descriptive studies is a comprehensive summarization, in everyday terms, of specific events experienced by individuals or groups of individuals. Qualitative descriptive studies are the least "theoretical" of all of the qualitative approaches to research.

\subsection{Software Development Methodology}

The researchers chose incremental prototyping method in the development of the mixed reality application. Incremental prototyping method focused on the simple implementation of the software and interactively enhance its prototype until the full version of the software was achieved and acceptable by the end users. In the development of the software the researchers engaged the primary users and IT experts in identifying the possible errors and suggestions for the improvement of the application. The prototype of the application helped the researchers attain a good human computer interaction for the application. Figure 2 shows the incremental prototyping methodology model.

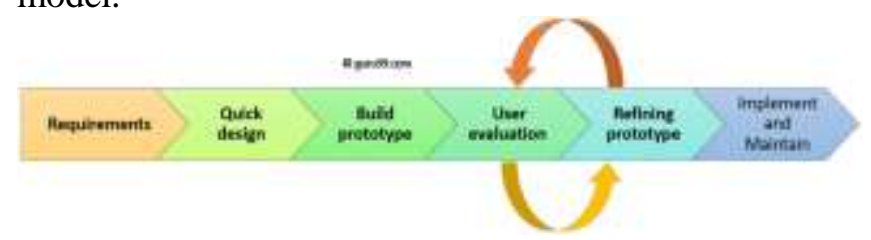

Figure 2. Incremental Prototyping Methodology Model
Requirements - The researchers gathered initial requirements from the experts who are in the field of information technology and sciences. Teachers teaching science specifically astronomy subject was interviewed by the researchers to gather necessary information about the solar system.

Quick Design - In this phase, the researchers started to design the prototype of the mixed reality application and evaluated the design by the IT experts and science teachers. The researchers started to model the 3D models of the planets in the solar system.

Build Prototype - In this phase, the researchers started to build the prototype of the application by incorporating all the 3D models of the planets. The positions and descriptions of the planets were based on the suggestions of the science teachers and through several researches available in the internet.

User evaluation - In this phase, the IT experts and science teachers evaluated the prototype and expressed their recommendations about their experience using the application. The comments and suggestions were written in the survey questionnaire provided by the researchers. The researchers based its survey questionnaire using the international software quality standard criteria.
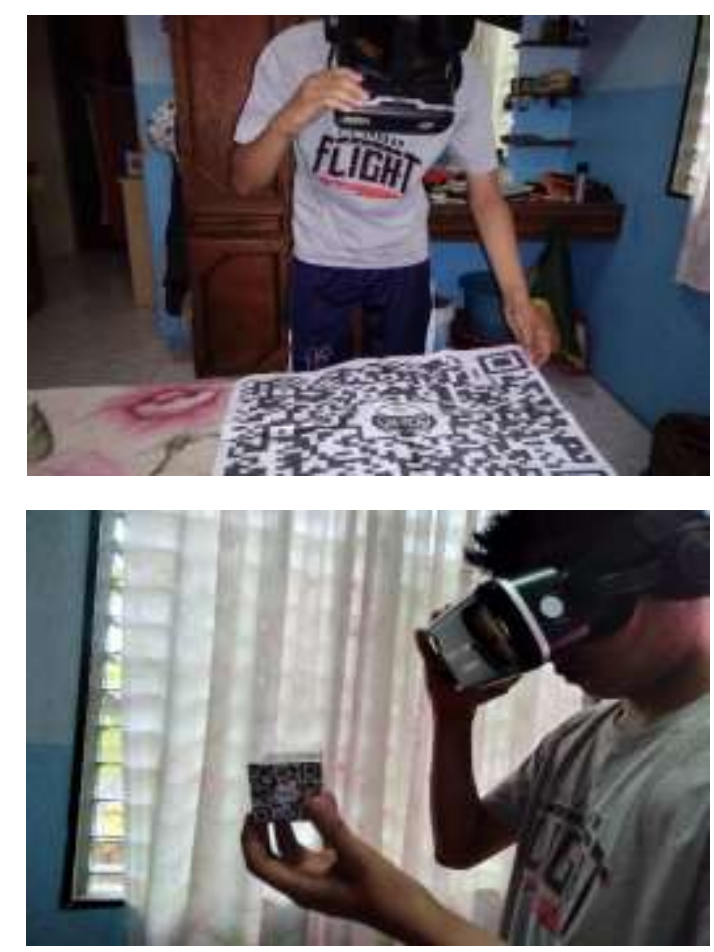

Figure 3.Testing of the Prototype Application

Refining prototype - After collecting all the suggestions and recommendations of the evaluators of the application, this phase is now the time to correct and improve the prototype application. The researchers 
continuously gather recommendations from the experts to further improve the prototype application.

Implement and Maintain - The final application through series of test was produced as a product of the collaboration of the researchers and the experts. The application was used as an innovative way of teaching science in junior high school.

\subsection{Population, Sample Size and Sampling Technique}

The respondents of the study were twenty (20) students from Grade 9 under the Science, Technology and Engineering Program (STEP) program at Subic National High School and five (5) experts comprised of three (3) Computer-Aided Design (CAD) designers and two (2) programmers participated in the system evaluation. Specifically, responses of respondents were taken during the initial testing of the system and asked to answer the survey questionnaire prepared by the researchers.

Table 1. Distribution of the Respondents in Terms of Specification

\begin{tabular}{ll}
\hline Specification & Frequency \\
\hline Grade 9 STEP students & 20 \\
IT Experts & 5 \\
\hline Total & 25 \\
\hline
\end{tabular}

Table 1. demonstrates the number of respondents per specification. The researcher's selection of respondents was based on the availability of the respondents in Grade 9 STEP program present during the pilot testing of the application. Respondents were suggested by the head of the Science Technology and Engineering Program (STEP) at Subic National High School. The respondents were exposed on the system usability and usefulness before answering the survey questionnaire. Five (5) IT experts were also selected to measure the effectiveness and efficiency of the application.

\subsection{Research Instruments}

Research Instruments were designed to obtain data on a topic of interest from research subjects. These are the fact findings strategies. They are tools for data collections. Evaluation instrument were also used by the researchers to assess the quality of the finished product.

\subsection{Data Gathering Instruments}

\subsubsection{Interviews}

Interviews become necessary when researchers feel the need to meet face-to-face with the individuals to interact and generate ideas in a discourse that borders on mutual interest. It is an interaction in which oral question are posed by the interviewer to elicit oral response from the interviewee.

\subsubsection{Observation}

Observation is one of the very important methods for obtaining comprehensive data in qualitative research especially when a composite of both oral and visual data become vital to the research. The researchers used an audio-visual recorder for a complete collection of such comprehensive record.

\subsection{Evaluation Instrument}

\subsubsection{Survey Questionnaire}

Survey questionnaire is one way of measuring the efficiency and effectiveness of the developed application. It is designed to answer the evaluation questions based on the user's experience in the testing of the application. The researchers based their survey questionnaire in ISO 9126-1 Software Quality Standard for Software Development Projects.

\subsubsection{Screen Shoots}

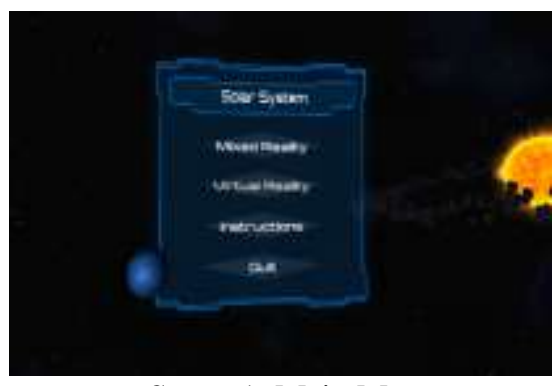

Scene 1. Main Menu

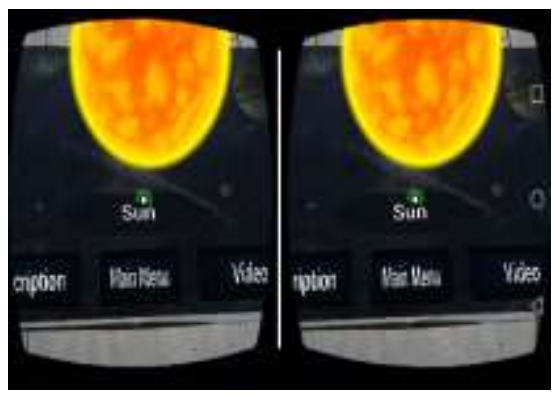

Scene 2. Categories

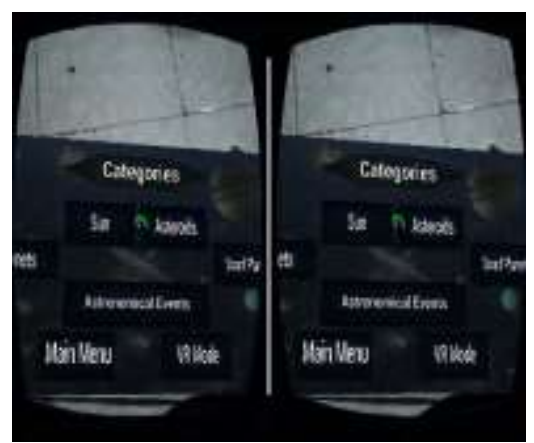

Scene 3. Sun Visualization 


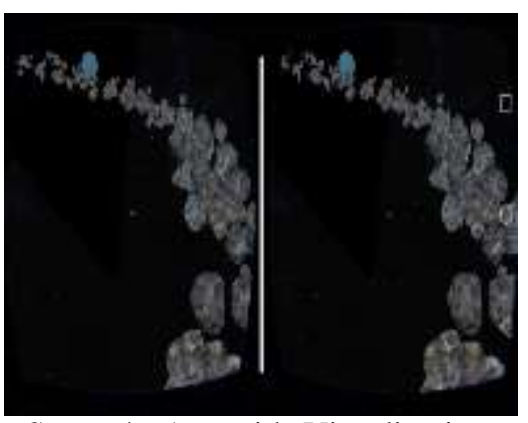

Scene 4. Asteroids Visualization

\subsection{Data-Gathering Procedure}

The researchers used the questionnaire to gather the desired data to the locale. The researchers seek the endorsement of the Subic National High School Science Department Head since they were the primary beneficiary of the developed application. Series of interviews were done by the researchers to gather data relative to the model and description of each planet in the solar system. To measure the efficiency and effectiveness of the developed application, survey questionnaire that had been validated by experts and panel members had been distributed to the respondents, the researchers assuring the respondents that the data gathered would be treated with utmost confidentiality. The results gathered were tallied and tabulated according to the frequency (weighted mean) of the items checked by the respondents. After the tabulation, results were interpreted using various statistical tools.

\subsection{Statistical Treatment of Data}

This section will discuss the statistical tools used in the gathered data and determining the equivalent interpretation using the Likert scale used in the evaluation questionnaire. Statistical analysis of data was used to show and explain how the data were concentrated and to understand the distribution of the data. The statistical treatment used by the researchers were discussed below. Weighted Mean. This was used to determine the level of agreement and disagreement of the respondents in evaluating the nonfunctional requirements of the system.

Formula: $\mathrm{X}=\Sigma \mathrm{wx} / \Sigma \mathrm{w}$

Where: $\Sigma x=$ the sum of the responses (response, $x$, multiplied by weights, w)

$\Sigma \mathrm{W}=$ the sum of respondents

A Five scale Likert was used in the questionnaires to determine the level of agreement and disagreement of the users given a criterion. The following table shows the verbal interpretation of the Likert scale with the weighed mean which is the result of the consolidated points from the respondents' answers to each item in the questionnaire.
Table 2. Likert Scale and Weighted Mean Rate

\begin{tabular}{ccc}
\hline Weighted mean & Scale & Verbal Interpretation \\
\hline $4.21-5.00$ & 5 & Excellent \\
$3.41-4.20$ & 4 & Very Good \\
$2.61-3.40$ & 3 & Good \\
$1.81-2.60$ & 2 & Fair \\
$1.00-1.80$ & 1 & Needs Improvement \\
\hline
\end{tabular}

*Based on Rensis Likert model

\section{Result and Discussion}

Table 3.1. Data Interpretation of Students on Functionality in Efficiency of Mixed Reality Application of Solar System

\begin{tabular}{|c|c|c|c|c|c|c|c|}
\hline Criteria & 5 & 4 & 3 & 2 & 1 & $\begin{array}{l}\text { Total } \\
\text { WM }\end{array}$ & $\begin{array}{l}\text { Verbal } \\
\text { Interpretation }\end{array}$ \\
\hline A1 & 4.00 & 0.8 & 0 & 0 & 0 & 4.80 & Excellent \\
\hline $\mathrm{A} 2$ & 4.25 & 0.6 & 0 & 0 & 0 & 4.85 & Excellent \\
\hline A3 & 3.75 & 0.8 & 0.15 & 0 & 0 & 4.70 & Excellent \\
\hline \multicolumn{6}{|c|}{ Total Average Weighted Mean } & 4.78 & Excellent \\
\hline
\end{tabular}

Table 3.2. Data Interpretation of Experts on Functionality in Efficiency of Mixed Reality Application of Solar System

\begin{tabular}{llllllll}
\hline Criteria & 5 & 4 & 3 & 2 & 1 & $\begin{array}{c}\text { Total } \\
\text { WM }\end{array}$ & $\begin{array}{l}\text { Verbal } \\
\text { Interpretation }\end{array}$ \\
\hline A1 & 2.00 & 2.4 & 0 & 0 & 0 & 4.40 & Excellent \\
A2 & 3.00 & 1.6 & 0 & 0 & 0 & 4.60 & Excellent \\
A3 & 3.00 & 1.6 & 0 & 0 & 0 & 4.60 & Excellent \\
\hline
\end{tabular}

Total Average Weighted Mean $4.53 \quad$ Excellent

Where:

A1. All the information's displayed are up-to-date

A2. The system met the standard user requirement

A3. System application provides necessary information's (planets)

Table 3.1 shows the data interpretation of users under functionality. Students rating on criterion A1 was excellent or 4.80, suggesting that the application displayed up-to-date information's. Criterion A2 garnered a total weighted mean of 4.85 (Excellent). While in criterion A3, students answered were mostly 
likely excellent but there were some students who answered very good or simply good. Students ratings under Functionality was 4.78 (Excellent), suggesting that the application was functional to use.

Experts' ratings on the same criteria were excellent but there were some experts who answered very good that the application must improve its functionality. Table 3.2 shows the experts' ratings on functionality which garnered a total average weighted mean of 4.53 (Excellent) that the application displayed updated information's and meets its user's requirements.

Table 4.1 Data Interpretation of Students on Usability in Efficiency of Mixed Reality Application of Solar System

\begin{tabular}{llllllll}
\hline Criteria & 5 & 4 & 3 & 2 & 1 & $\begin{array}{l}\text { Total } \\
\text { WM }\end{array}$ & $\begin{array}{l}\text { Verbal } \\
\text { Interpretation }\end{array}$ \\
\hline B1 & 2.75 & 1.8 & 0 & 0 & 0 & 4.55 & Excellent \\
B2 & 3.75 & 0.8 & 0.15 & 0 & 0 & 4.70 & Excellent \\
B3 & 4.25 & 0.2 & 0.3 & 0 & 0 & 4.75 & Excellent \\
\hline \multicolumn{7}{l}{ Total Average Weighted Mean } \\
\hline
\end{tabular}

Table 4.1 shows the data interpretation of students on Usability. Data presented shows that students were satisfied on the usefulness of the developed application. Criterion B1, students' ratings were 4.55 (Excellent) while criterion B2 garnered a weighted mean of 4.70 (Excellent). The application provides menus and buttons that can be easily navigate has a weighted mean of 4.75 (Excellent).

Table 4.2 Data Interpretation of Experts on Usability in Efficiency of Mixed Reality Application of Solar System

\begin{tabular}{llllllll}
\hline Criteria & 5 & 4 & 3 & 2 & 1 & $\begin{array}{l}\text { Total } \\
\text { WM }\end{array}$ & $\begin{array}{l}\text { Verbal } \\
\text { Interpretation }\end{array}$ \\
\hline
\end{tabular}

$\begin{array}{llllllll}\text { B1 } & 1.00 & 1.60 & 1.20 & 0 & 0 & 3.80 & \text { Very Good } \\ \text { B2 } & 2.00 & 2.40 & 0 & 0 & 0 & 4.40 & \text { Excellent } \\ \text { B3 } & 1.00 & 3.20 & 0 & 0 & 0 & 4.20 & \text { Very Good }\end{array}$

Total Average Weighted Mean

4.13 Very Good

Where:

B1. Friendly User Interface

B2. Labels on each part of the program are clear and understandable

B3. Provides menus and buttons that can be easily navigate

Table 4.2 shows the experts' ratings were reverse to the student's evaluation were criterion B1 garnered a weighted mean of 3.80 or very good. Most of the experts answered very good on criterion B2 and B3 suggesting that the MR application must improve its menus and buttons for easy navigation. In overall, experts' ratings were 4.13 or very good that the MR application were usable to its purpose.

Table 5.1 Data Interpretation of Students on Efficiency in Efficiency of Mixed Reality Application of Solar System

\begin{tabular}{llllllll}
\hline Criteria & 5 & 4 & 3 & 2 & 1 & $\begin{array}{l}\text { Total } \\
\text { WM }\end{array}$ & Verbal \\
Interpretation & \\
C1 & 4.25 & 0.60 & 0 & 0 & 0 & 4.85 & Excellent \\
C2 & 3.25 & 1.20 & 0.15 & 0 & 0 & 4.60 & Excellent \\
C3 & 2.00 & 2.20 & 0.15 & 0 & 0 & 4.35 & Excellent \\
\hline \multicolumn{2}{l}{ Total Average Weighted Mean } & & 4.60 & Excellent \\
\hline
\end{tabular}

Table 5.2 Data Interpretation of Experts on Efficiency in Efficiency of Mixed Reality Application of Solar System

\begin{tabular}{cccccccc}
\hline Criteria & 5 & 4 & 3 & 2 & 1 & $\begin{array}{c}\text { Total } \\
\text { WM }\end{array}$ & $\begin{array}{c}\text { Verbal } \\
\text { Interpretation }\end{array}$ \\
\hline C1 & 1.00 & 3.20 & 0 & 0 & 0 & 4.20 & Very Good \\
C2 & 1.00 & 2.40 & 0.60 & 0 & 0 & 4.00 & Very Good \\
C3 & 0 & 3.20 & 0.60 & 0 & 0 & 3.80 & Very Good \\
\hline \multicolumn{7}{l}{ Total Average Weighted Mean } & \\
\hline
\end{tabular}
Where:
C1. Efficiently managed and utilized the resources
C2. Realistic view of the models (planets)
C3. Quality of voice over

Table 5.1 shows the data interpretation of students on Efficiency. MR application were efficiently managed its resources as shown in the students' ratings which garnered 4.85 (Excellent). Some students suggesting that the model planets must be improved. In criterion $\mathrm{C} 2$, students' ratings were excellent but there were some students who are not in favor of the presentation of the model planets.

A total weighted mean of 4.60 (Excellent) were gathered from the students. Experts' ratings however show that the utilization of resources of the developed application was excellent and the realistic view of the model planets were presented in the application. However, in criterion C3, experts suggested that the quality of voice over must be improved which has a 
total weighted mean of 3.80 or very good. Table 5.2 shows the experts' ratings on efficiency of the developed MR application which has a total average weighted mean of 4.00 (very good).

Table 6.1 Data Interpretation of Students on Portability in Efficiency of Mixed Reality Application of Solar System

\begin{tabular}{|c|c|c|c|c|c|c|c|}
\hline Criteria & 5 & 4 & 3 & 2 & 1 & $\begin{array}{l}\text { Total } \\
\text { WM }\end{array}$ & $\begin{array}{c}\text { Verbal } \\
\text { Interpretation }\end{array}$ \\
\hline D1 & 4.00 & 0.80 & 0 & 0 & 0 & 4.80 & Excellent \\
\hline D2 & 4.50 & 0.40 & 0 & 0 & 0 & 4.90 & Excellent \\
\hline D3 & 3.50 & 1.20 & 0 & 0 & 0 & 4.70 & Excellent \\
\hline \multicolumn{6}{|c|}{ Total Average Weighted Mean } & 4.80 & Excellent \\
\hline
\end{tabular}

Table 6.1 shows the data interpretation of students on Portability. The software application was easy to install in an android device as proved by the students' ratings of 4.80 (Excellent) but there are students who answered very good or simply good.

Table 6.2 Data Interpretation of Experts on Portability in Efficiency of Mixed Reality Application of Solar System

\begin{tabular}{cccccccc}
\hline Criteria & 5 & 4 & 3 & 2 & 1 & $\begin{array}{c}\text { Total } \\
\text { WM }\end{array}$ & $\begin{array}{c}\text { Verbal } \\
\text { Interpretation }\end{array}$ \\
\hline D1 & 2.00 & 2.40 & 0 & 0 & 0 & 4.40 & Excellent \\
D2 & 3.00 & 0.80 & 0.60 & 0 & 0 & 4.40 & Excellent \\
D3 & 3.00 & 0.80 & 0.60 & 0 & 0 & 4.40 & Excellent \\
\hline \multicolumn{7}{l}{ Total Average Weighted Mean } \\
\hline
\end{tabular}

Where:

D1. Software application can be installed in its specified environment

D2. Easy to install (android)

D3. Software supports needed plug-ins for viewing (VR box)

Table 6.2 shows experts' ratings on the same criteria were also excellent or 4.40 suggesting the application developed could be installed in an android device. The installation of the MR application to an android device were based on the software requirements. Experts' answered were largely in agreement with the student's ratings were the developed MR application is easy to install.

Table 7.1. Data Interpretation of Students on Users Acceptance

\begin{tabular}{|c|c|c|c|c|c|c|c|}
\hline Criteria & 5 & 4 & 3 & 2 & 1 & WM & $\begin{array}{l}\text { Verbal } \\
\text { Interpretation }\end{array}$ \\
\hline 1. The user interface is easy to use. & 3.00 & 1.60 & 0 & 0 & 0 & 4.60 & Excellent \\
\hline $\begin{array}{l}\text { 2. The user interface contains all the necessary } \\
\text { functions at first glance. }\end{array}$ & 3.00 & 1.60 & 0 & 0 & 0 & 4.60 & Excellent \\
\hline 3. The user interface allows easy navigation. & 3.75 & 0.80 & 0.15 & 0 & 0 & 4.70 & Excellent \\
\hline $\begin{array}{l}\text { 4. The graphics present a clear distinction } \\
\text { between the different elements of the } \\
\text { program. }\end{array}$ & 4.50 & 0.40 & 0 & 0 & 0 & 4.90 & Excellent \\
\hline $\begin{array}{l}\text { 5. The graphics is intuitive and represents their } \\
\text { function / basis. }\end{array}$ & 3.25 & 1.20 & 0.15 & 0 & 0 & 4.60 & Excellent \\
\hline 6. The graphics does not cause confusion. & 3.25 & 1.20 & 0.15 & 0 & 0 & 4.60 & Excellent \\
\hline $\begin{array}{l}\text { 7. The application presents additional learning } \\
\text { environment. }\end{array}$ & 4.75 & 0.20 & 0 & 0 & 0 & 4.95 & Excellent \\
\hline $\begin{array}{l}\text { 8. The program is able to provide its specified } \\
\text { functions. }\end{array}$ & 4.25 & 0.60 & 0 & 0 & 0 & 4.85 & Excellent \\
\hline Total Average Weighted Mean & & & & & & 4.15 & Very Good \\
\hline
\end{tabular}

Table 7.1 shows the users acceptance of students on the developed application. Criteria 1,2,5 and 6 are in agreement with each other suggesting that the developed MR application was easy to use, contains necessary information, the graphics is pleasing to look at and it does not cause confusion to the users with a total weighted mean of 4.60 (Excellent). The navigation to the interface garnered a weighted mean of 4.70 (Excellent) while distinction of the different elements in the program has a total weighted mean of 4.90 (Excellent). The user was satisfied to the performance of the application and thus, was able to provides its specified functions with a total weighted mean of 4.85 (Excellent). In overall ratings, the students rated the application as very good or a total average weighed mean of 4.15 . 


\begin{tabular}{|c|c|c|c|c|c|c|c|}
\hline Criteria & 5 & 4 & 3 & 2 & 1 & WM & $\begin{array}{l}\text { Verbal } \\
\text { Interpretation }\end{array}$ \\
\hline 1. The user interface is easy to use. & 1.00 & 3.20 & 0 & 0 & 0 & 4.20 & Very Good \\
\hline $\begin{array}{l}\text { 2. The user interface contains all the necessary } \\
\text { functions at first glance. }\end{array}$ & 1.00 & 3.20 & 0 & 0 & 0 & 4.20 & Very Good \\
\hline 3. The user interface allows easy navigation. & 1.00 & 3.20 & 0 & 0 & 0 & 4.20 & Very Good \\
\hline $\begin{array}{l}\text { 4. The graphics present a clear distinction between } \\
\text { the different elements of the program. }\end{array}$ & 5.00 & 0 & 0 & 0 & 0 & 5.00 & Excellent \\
\hline $\begin{array}{l}\text { 5. The graphics is intuitive and represents their } \\
\text { function / basis. }\end{array}$ & 1.00 & 3.20 & 0 & 0 & 0 & 4.20 & Very Good \\
\hline 6. The graphics does not cause confusion. & 5.00 & 0 & 0 & 0 & 0 & 5.00 & Excellent \\
\hline $\begin{array}{l}\text { 7. The application presents additional learning } \\
\text { environment. }\end{array}$ & 1.00 & 3.20 & 0 & 0 & 0 & 4.20 & Very Good \\
\hline $\begin{array}{l}\text { 8. The program is able to provide its specified } \\
\text { functions. }\end{array}$ & 5.00 & 0 & 0 & 0 & 0 & 5.00 & Excellent \\
\hline Total Average Weighted Mean & & & & & & 4.50 & Excellent \\
\hline
\end{tabular}

Table 7.2 shows the experts' ratings on user's acceptance. Criteria 1, 2, 3, 5 and 9 garnered the same total weighted mean of 4.20 or very good. Experts' ratings were in agreement with each other suggesting that the application must improve its menus and buttons for easy navigation and the presentation of models to avoid confusion must also be enhanced. In criteria 4, 6 and 10 shows that experts; ratings were largely in agreement with each other with a total weighted mean of 5.00 or excellent. Ratings of experts on the criteria under user acceptance garnered a total average weighted mean of 4.50 (Excellent) were it shows that experts suggesting the use of the MR application for additional learning tool for teaching solar system.

Table 8 Summary on the Effectiveness of the Application (Students)

\begin{tabular}{rll}
\hline $\begin{array}{l}\text { Effectiveness Based on } \\
\text { the Various Aspects }\end{array}$ & WM & Rank \\
\hline 1. Functionality & 4.78 & 2 \\
2. Usability & 4.66 & 3 \\
3. Efficiency & 4.60 & 4 \\
4. Portability & 4.80 & 1 \\
\hline Total Weighted Mean & 4.71 & \\
\hline
\end{tabular}

Table 8 shows the summary and ranking of the weighted mean in each criterion in the application's effectiveness based on the answers of the respondents. Portability is the highest with a total.

Table 9 shows the summary and ranking of the weighted mean in each criterion in the application's effectiveness based on the answers of the respondents.
Functionality is the highest with the total weighted mean of 4.53. Second is the portability with the total weighted mean of 4.40 . Third is the Usability with the total weighted mean of 4.13 and the lowest among the criteria is the efficiency with the total weighted mean of 4.00 .

Table 9 Summary on the Effectiveness of the Application (Experts)

\begin{tabular}{ccc}
\hline $\begin{array}{c}\text { Effectiveness Based on } \\
\text { the Various Aspects }\end{array}$ & WM & Rank \\
\hline 1. Functionality & 4.53 & 1 \\
2. Usability & 4.13 & 3 \\
3. Efficiency & 4.00 & 4 \\
4. Portability & 4.40 & 2 \\
\hline \multicolumn{2}{l}{ Total Weighted Mean } & 4.26 \\
\hline
\end{tabular}

Table 10 shows the answers and ranking of the weighted mean in each criterion in the user's acceptance based on the answers of the respondents on the proposed application. This shows how they viewed and understood the proposed application. With a total weighted mean of 4.15 falls right into the interpretation of" Very good". The highest is criterion No.7 ranked 1 with the total weighted mean of 4.95. Criterion No.4 ranked 2 with the total weighted mean of 4.90 .

Criterion No. 8 ranked 3 with the total weighted mean of 4.80. Criterion no. 3 ranked 4 with the total weighted mean of 4.70 while Criterion No. 1,25 and 6 ranked 5 with the same total weighted mean of 4.60 . 
Table 10 Data Interpretation of Students on Users Acceptance

\begin{tabular}{|c|c|c|c|c|c|c|c|c|c|}
\hline \multicolumn{2}{|c|}{ Criteria } & \multirow{2}{*}{$\begin{array}{l}5 \\
3.00\end{array}$} & \multirow{2}{*}{4} & \multirow{2}{*}{3} & \multirow{2}{*}{2} & \multirow{2}{*}{1} & \multirow{2}{*}{ WM } & \multirow{2}{*}{$\begin{array}{l}\text { Verbal } \\
\text { Interpretation }\end{array}$} & \multirow{2}{*}{$\begin{array}{l}\text { Rank } \\
5\end{array}$} \\
\hline 1. & The user interface is easy to use. & & & & & & & & \\
\hline 2. & $\begin{array}{l}\text { The user interface contains all the necessary } \\
\text { functions at first glance. }\end{array}$ & 3.00 & 1.60 & 0 & 0 & 0 & 4.60 & Excellent & 5 \\
\hline 3. & The user interface allows easy navigation. & 3.75 & 0.80 & 0.15 & 0 & 0 & 4.70 & Excellent & 4 \\
\hline 4. & $\begin{array}{l}\text { The graphics present a clear distinction } \\
\text { between the different elements of the } \\
\text { program. }\end{array}$ & 4.50 & 0.40 & 0 & 0 & 0 & 4.90 & Excellent & 2 \\
\hline 5. & $\begin{array}{l}\text { The graphics is intuitive and represents their } \\
\text { function / basis. }\end{array}$ & 3.25 & 1.20 & 0.15 & 0 & 0 & 4.60 & Excellent & 5 \\
\hline 6. & The graphics does not cause confusion. & 3.25 & 1.20 & 0.15 & 0 & 0 & 4.60 & Excellent & 5 \\
\hline 7. & $\begin{array}{l}\text { The application presents additional learning } \\
\text { environment. }\end{array}$ & 4.75 & 0.20 & 0 & 0 & 0 & 4.95 & Excellent & 1 \\
\hline 8. & $\begin{array}{l}\text { The program is able to provide its specified } \\
\text { functions. }\end{array}$ & 4.25 & 0.60 & 0 & 0 & 0 & 4.85 & Excellent & 3 \\
\hline Tot & l Average Weighted Mean & & 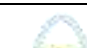 & & & & 4.15 & Very Good & \\
\hline
\end{tabular}

Table 11 Data Interpretation of Experts on Users Acceptance

\begin{tabular}{|c|c|c|c|c|c|c|c|c|}
\hline Criteria & 5 & 4 & 3 & 2 & 1 & WM & $\begin{array}{l}\text { Verbal } \\
\text { Interpretation }\end{array}$ & Rank \\
\hline 1. The user interface is easy to use. & 1.00 & 3.20 & 0 & 0 & 0 & 4.20 & Very Good & 2 \\
\hline $\begin{array}{l}\text { 2. The user interface contains all the necessary } \\
\text { functions at first glance. }\end{array}$ & 1.00 & 3.20 & 0 & 0 & 0 & 4.20 & Very Good & 2 \\
\hline 3. The user interface allows easy navigation. & 1.00 & 3.20 & 0 & 0 & 0 & 4.20 & Very Good & 2 \\
\hline $\begin{array}{l}\text { 4. The graphics present a clear distinction } \\
\text { between the different elements of the } \\
\text { program. }\end{array}$ & 5.00 & 0 & 0 & 0 & 0 & 5.00 & Excellent & 1 \\
\hline $\begin{array}{l}\text { 5. The graphics is intuitive and represents their } \\
\text { function / basis. }\end{array}$ & 1.00 & 3.20 & 0 & 0 & 0 & 4.20 & Very Good & 2 \\
\hline 6. The graphics does not cause confusion. & 5.00 & 0 & 0 & 0 & 0 & 5.00 & Excellent & 1 \\
\hline $\begin{array}{l}\text { 7. The application presents additional learning } \\
\text { environment. }\end{array}$ & 1.00 & 3.20 & 0 & 0 & 0 & 4.20 & Very Good & 2 \\
\hline $\begin{array}{l}\text { 8. The program is able to provide its specified } \\
\text { functions. }\end{array}$ & 5.00 & 0 & 0 & 0 & 0 & 5.00 & Excellent & 1 \\
\hline Total Average Weighted Mean & & & & & & 4.50 & Excellent & \\
\hline
\end{tabular}


Table 11 shows the answers and ranking of the weighted mean in each criterion in the user's acceptance based on the answers of the respondents on the proposed application. This shows how they viewed and understood the proposed application with a total weighted mean of 4.50 falls right into the interpretation of" Excellent". The Criteria No. 4,8 and 6 ranked 1 with the same weighted mean of 5 . The criteria No. 1,2,3,5 and 7 ranked 2 with the same weighted mean of 4.20 . It is also concluded that the level of user's acceptance, with 4.15 and 4.50 the result shows that both respondents accept the system. The users commented about the systems responsiveness and they are all glad about the real time response of the system. It is therefore recommended the use of the mixed reality application in teaching science to enhance more the knowledge and skills of the STEM students in learning solar system.

\section{Conclusion and Recommendations}

The mixed reality application of solar system, an immersive software application will be a great help to the students to be more engage in class discussion and the most important thing is they will gain knowledge while enjoying the class. The result of the study shows

that the students and experts perception towards the system's efficiency and effectiveness based on the criteria Functionality, Usability, Efficiency and Portability as stated on the results on the chapter 3 Findings and interpretation both respondents rate the system with $4.78,4.66,4.60,4,80$ respectively on the students and with $4.53,4.13,4.60,4.40$ on the experts result shows that both respondents rate excellent

\section{References}

[1]. Cheng, Kun-Hung and Chin-Chung Tsai (2012) Affordances of Augmented Reality in Science Learning: Suggestions for Future Research. Retrieve from https://link.springer.com/ article/10.1007/s10956-012-9405-9.

[2]. Ko, Sang Min \& Chang, Won \& Ji, Yong Gu. (2013). Usability Principles for Augmented Reality Applications in a Smartphone Environment. International Journal of HumanComputer Interaction. 29. 10.1080/10447318.2012.722466.

[3]. Weng, Cathy \& Rathinasabapathi, Abirami \& Weng, Apollo \& Lonardy, Cindy. (2018). Mixed Reality in Science Education as a Learning Support: A Revitalized Science Book. Journal of Educational Computing Research. 57. 073563311875701. $10.1177 / 0735633118757017$.
[4]. FitzGerald, Elizabeth \& Ferguson, Rebecca \& Adams, Anne \& Gaved, Mark \& Mor, Yishay \& Thomas, Rhodri. (2015). Augmented Reality and Mobile Learning: International Journal of Mobile and Blended Learning. 5. 4358. 10.4018/ijmbl.2013100103.

[5]. Ladwig, Philipp \& Geiger, Christian. (2018). A Literature Review on Collaboration in Mixed Reality. 